triggered local reviews in UK maternity units in order to inform future guidance for confidential case reviews of severe maternal morbidities.

Methods All consultant-led maternity units in the UK were contacted up to three times and asked to supply a copy of the checklist of incidents which triggered a local review. The lists were tabulated and compared with incidents recommended for review by the Royal College of Obstetricians and Gynaecologists (RCOG).

Results Among the 211 consultant-led maternity units in the UK, $72 \%$ provided an incident review trigger list. The conditions covered were highly variable, although those recommended by the RCOG were most highly represented. Over $90 \%$ of units who responded included maternal and neonatal deaths, stillbirths, intensive care admissions, severe haemorrhage $(>1500 \mathrm{ml})$ and shoulder dystocia. Between $80-90 \%$ of units also listed eclampsia, uterine rupture, medication error and other organisational incidents. Only $73 \%$ of units listed hysterectomy, $66 \%$ cardiac arrest and $62 \%$ maternal sepsis or a severe infection.

Conclusions Significant variation exists between units in the number and type of conditions reviewed. Importantly, less than two thirds of units specifically review cases of severe infective complications, despite current concerns about a rising rate of maternal death due to sepsis.

\section{PM.39 POSTNATAL RISK ASSESSMENT OF VENOUS THROMBOEMBOLISM (VTE)}

doi:10.1136/archdischild-2013-303966.121

'DA Banfield, ${ }^{2} \mathrm{LM}$ Page, ${ }^{2} \mathrm{CS}$ Cotzias, ${ }^{2} \mathrm{JC}$ Girling. ${ }^{1} / \mathrm{mperial}$ College London, London, UK, ${ }^{2}$ West Middlesex University Hospital, Middlesex, UK

VTE is the third leading cause of maternal death in the UK ${ }^{1}$. In our unit, risk of VTE is assessed using a scoresheet based on RCOG guidelines ${ }^{2}$, and low molecular weight heparin (LMWH) prescribed according to risk. A recent case of VTE associated with incorrect scoring prompted this audit into the system's use.

This was a prospective audit, over a 2 week period in October 2012. Spot cheques, carried out on the Postnatal ward, assessed how many women had a completed score sheet, the accuracy of their scores, and identified factors contributing to inaccuracies. When the score indicated a need for LMWH, prescriptions were evaluated.

60 sets of notes were reviewed: 24 women had vaginal deliveries (SVD), 24 delivered by Caesarean section (CS) and 10 had instrumental deliveries (ID).

Only $43[72 \%]$ women had a completed scoresheet: $60 \%$ of IDs, $96 \%$ of CS, $50 \%$ of SVDs. Of these, $74 \%$ were scored correctly: 2 were given the wrong $\mathrm{LMWH}$ dose. Of the women with incorrect scores, 4 prescribing errors were identified. 2 women without completed scoresheets required LMWH. All 8 prescribing errors were corrected

The audit showed three main types of scoring error: clinical subjectivity, administrative and human factor.

More work is required to encourage staff to consider VTE risk assessment a vital part of a woman's care. The scoresheet should be included in the delivery notes and become a compulsory part of patient handover. Its use will be reaudited.

\section{REFERENCES}

1. Centre for maternal and child enquiries. Saving Mothers' Lives: Reviewing Maternal Deaths to Make Motherhood Safer, 2006-2008. The Eighth Report of the Confidential Enquiries into Maternal Deaths in the United Kingdom. London: CMACE March 2011.

2. Royal College of Obstetricians and Gynaecologists. Green top Guideline No.37a: Reducing the risk of Thrombosis and Embolism during Pregnancy and the Puerperium. November 2009.

\section{PM.40 LIFESTYLE INTERVENTION REDUCES THE NEED FOR INSULIN THERAPY AND MACROMIA IN GESTATIONAL DIABETES MELLITUS}

doi:10.1136/archdischild-2013-303966.122

${ }^{1,2} \mathrm{CE}$ Walsh, 'M Coffey, ${ }^{1} \mathrm{U}$ Daniel, 'E Byrne, ${ }^{1} \mathrm{C}$ Gavin, ${ }^{1} \mathrm{R}$ Firth, ${ }^{1,2} \mathrm{~F}$ McAuliffe, ${ }^{1,2} \mathrm{M}$ Foley. ${ }^{1}$ National Maternity Hospital, Dublin, Ireland; ${ }^{2}$ University College Dublin, Dublin, Ireland

Introduction In 2011 "life style intervention" was introduced in addition to a low glycaemic diet and insulin (when required), for management of patients diagnosed with gestational diabetes (GDM) at the National Maternity Hospital.

Methods A prospective study of the potential benefit of lifestyle intervention versus standard management in the treatment of gestational diabetes mellitus.

Lifestyle management included group education on diet and exercise and a personal glucometer for home blood sugar monitoring, reinforced at least weekly contact with the diabetic team. Data on demographics, insulin use and macrosomia was collected.

Results In the period 2008-2010, 412 cases with GDM received standard management and from 2011 onwards, data was available on 353 cases of GDM following the introduction of life style intervention. Patient demographics were similar in both groups and there was no significant difference in mean age, BMI, gestational weight gain and ethnicity between the two groups. In the preintervention cohort, $40.7 \%(168 / 412)$ were treated with insulin, compared with $22 \%(78 / 353)$ post intervention $(p<0.001)$. The incidence of macrosomia (birth weight $>90 \%$ centile for gestational age) was 20\% prior to 2011 (84/412) and 13.8\% (49/353) following intervention $(p<0.04)$ ( Table 1$)$

Conclusion The results show that the intervention has almost halved the need for insulin treatment in patients with GDM without any compromise in fetal outcome. The results strongly suggest that a randomised trail of life style intervention should be conducted.

\section{Abstract PM.40 Table}

\begin{tabular}{llll}
\hline & Pre-intervention & Post-intervention & \\
\hline Number & 412 & 353 & \\
Insulin treatment & $168(40.7 \%)$ & $78(22.9 \%)$ & $\mathrm{P}<0.001$ \\
Macrosomia & $84(20 \%)$ & $49(13.8 \%)$ & $\mathrm{P}<0.04$ \\
\hline
\end{tabular}

\section{PM.41 CAN PULSE WAVE ANALYSIS PREDICT ADVERSE OBSTETRIC OUTCOME IN PREGNANT WOMEN WITH CHRONIC HYPERTENSION?}

doi:10.1136/archdischild-2013-303966.123

R Cockerill, C Chmiel, I Crocker, J Myers. Maternal and Fetal Health Research Centre, St Mary's Hospital, Manchester, Manchester, UK

Introduction Complications of pregnancy including super imposed pre-eclampsia (PE), fetal growth restriction (FGR) and preterm delivery are common in women with chronic hypertension. Outside of pregnancy measurement of arterial stiffness using pulse wave analysis is highly predictive of future cardiovascular events. We aimed to assess the utility of pulse wave analysis in pregnancy in a cohort of women with chronic hypertension.

Methods Using the Tensioclinic ${ }^{\mathrm{TM}}$ arteriograph, women with hypertension attending a specialist clinic had longitudinal haemodynamic measurements taken at three time points from early pregnancy. Measurements included peripheral BP, central BP and pulse wave velocity (PWv).

Results To date pregnancy outcome data are available in 24 women. In women with an adverse obstetric outcome (preterm 
delivery, superimposed PE and/or FGR; $\mathrm{n}=14)$ the median gestation at delivery was 36.5 (26-38) vs 37.8 (37-39) weeks in the good outcome group $(\mathrm{n}=10)$. Customised birthweight centiles were significantly lower in the poor outcome group [10 (0-86) vs 67 (15-96); p < 0.05], BMI was not different between the groups. There was a trend towards a higher PWv in the poor outcome group at 16 weeks $9.29 \pm 1.66$ vs $8.21 \pm 1.06 \mathrm{~m} / \mathrm{s}$ $(\mathrm{p}=0.09)$. Peripheral $(101 \pm 10.6 \mathrm{vs} 97.9 \pm 8.6 \mathrm{mmHg})$ and central $(90.5 \pm 9.9$ vs $87.2 \pm 8.7 \mathrm{mmHg})$ mean arterial pressure were not different between the groups at the same gestation. There was no difference in the PWv between the groups at 22 weeks gestation.

Conclusion Measures of arterial stiffness in early pregnancy may be more informative than blood pressure measurements alone in the prediction of adverse pregnancy outcome in women with chronic hypertension.

\section{PM.42 HEPATITIS C ASSOCIATED THROMBOCYTOPENIA IN PREGNANCY: PREGNANCY MANAGEMENT AND MORBIDITY}

doi:10.1136/archdischild-2013-303966.124

${ }^{1} \mathrm{C}$ Monteith, 'S Cooley, ${ }^{2} \mathrm{~J}$ Lambert, ${ }^{2 B}$ Kelleher, 1,2F Ni Ainle, 'M Eogan. ${ }^{1}$ Rotunda Hospital, Dublin, Ireland; ${ }^{2}$ Mater Hospital, Dublin, Ireland

Hepatitis $\mathrm{C}$ virus (HCV) is associated with massive worldwide morbidity and mortality. Recent studies have implicated HCV in pathogenesis of immune thrombocytopenia. ${ }^{12}$ However, the impact in pregnancy has not been explored in detail.

We looked at the impact of HCV on maternal platelet count, bleeding and multidisciplinary management of labour and delivery in a retrospective series of HCV-infected pregnant women. Women with a detectable HCV viral load were identified between 2009 and 2011. Platelet count and HCV viral load were determined at booking, 32/40 and delivery in HCV-infected women and controls.

Thrombocytopenia was identified in $10.3 \%$ of $\mathrm{HCV}$-infected pregnant women in comparison to only $2.1 \%$ of age-matched controls $(p<0.01)$. Mean platelet count at delivery was significantly lower in HCV-infected women compared with controls $(p=0.01)$. There was no significant difference in estimated blood loss (EBL) at delivery. Regional anaesthesia was performed in $73 \%$ of thrombocytopenic HCV-infected women.

In the first study to date to investigate the impact of thrombocytopenia upon pregnancy management in HCV-infected women. We demonstrated a significantly higher frequency of thrombocytopenia and a significantly lower platelet count in HCV-infected pregnant women compared with controls. We recorded no significant fetal bleeding complications.

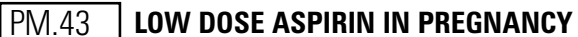

doi:10.1136/archdischild-2013-303966.125

DD Boban, E Ferguson, M Farquharson. Wishaw General Hospital, Glasgow, UK

Introduction Hypertensive disorders in pregnancy are associated with significant risks to both mother and baby. NICE recommends women at high risk of pre-eclampsia to be given $75 \mathrm{mgs}$ of Aspirin from 12 weeks gestation until delivery.

${ }^{1}$ Rajan, S.K., B.M. Espina, and H.A. Liebman, Hepatitis C virus-related thrombocytopenia: clinical and laboratory characteristics compared with chronic immune thrombocytopenic purpura. Br J Haematol, 2005. 129(6): p. 818-24.

${ }^{2}$ Zhang, W., et al, Role of molecular mimicry of hepatitis $\mathrm{C}$ virus protein with platelet GPIIIa in hepatitis C-related immunologic thrombocytopenia. Blood, 2009. 113(17): p. 4086-93.
Aim To review current practise on use of low dose aspirin in pregnancy for prevention of pre-eclampsia and to establish safety and benefit of its use.

Method Data were collected retrospectively for 295 patients who booked in for antenatal care between Jan 2010 and Jan 2011. The presence of risk factors for pre-eclampsia, use of low-dose aspirin, antenatal complications and delivery outcomes were recorded on a database and analysed. We investigated whether all eligible women were given aspirin and compared outcomes amongst those eligible who were given aspirin against those eligible who were not given aspirin.

Results $26 \%$ of all antenatal bookers were eligible for low dose aspirin of which only $18 \%$ were given aspirin. None of the patients who were eligible and prescribed aspirin developed preeclampsia as opposed to $7 \%$ in those who were eligible and did not receive aspirin. There was also a reduction in induction of labour (21\% and $38 \%$ ) with use of low dose aspirin, but no influence on gestation at delivery, mode of delivery, birth weight or admission to NNU.

Conclusions The use of low-dose aspirin is safe with no side effects in study group and beneficial in prevention of pre-eclampsia. Midwives have been issued with pocket guides to indications for aspirin to improve compliance.

\section{PM.44 PREGNANCY OUTCOMES IN BLACK WOMEN WITH CHRONIC HYPERTENSION IN THE UK}

doi:10.1136/archdischild-2013-303966.126

M Homsy, K Bramham, B Parnell, C Nelson-Piercy, LC Chappell. King's College London, London, UK

Introduction Women with chronic hypertension (CHT) have poor pregnancy outcomes. Black ethnicity is associated with both adverse pregnancy events, and CHT. Data regarding pregnancy outcome for black women in the UK are limited. Aims: 1) To assess pregnancy outcomes in women with CHT according to ethnicity; 2) To evaluate changes in pregnancy outcome over a decade

Methods Women with CHT who delivered at St. Thomas' Hospital between 2001-2011 were identified from a hospital database, and pregnancy outcomes extracted. Outcomes between black and white women were compared. Multiple pregnancies were excluded.

Results Black women had significantly worse neonatal outcomes than white women with CHT (Table). There were no significant differences in CHT pregnancy outcome between 2001-2011.

\section{Abstract PM.44 Table 1}

\begin{tabular}{|c|c|c|c|}
\hline Outcome & $\begin{array}{l}\text { Black } \\
(N=564)\end{array}$ & $\begin{array}{l}\text { White } \\
(N=367)\end{array}$ & ${ }^{*}$ Adjusted OR \\
\hline Still birth & $11(2 \%)$ & $3(1 \%)$ & $2.41(0.67-8.71)$ \\
\hline $\begin{array}{l}\text { Gestation at delivery (w) } \\
\text { Median(IOR) }\end{array}$ & $38(33-40)$ & $39(38-40)^{* *}$ & - \\
\hline Delivery $<34$ weeks & $59(10.5 \%)$ & $12(3.2 \%)$ & 7.25 (2.67-19.74) \\
\hline Delivery $<37$ weeks & $129(22.9 \%)$ & $41(10.8 \%)$ & $2.91(1.68-5.03)$ \\
\hline $\begin{array}{l}\text { Birthweight (g) } \\
\text { Median(IQR) }\end{array}$ & $\begin{array}{l}\text { AB3060 } \\
(2560-3500)\end{array}$ & $\begin{array}{l}\text { AB3300 } \\
(2920-3700)^{*}\end{array}$ & - \\
\hline $\begin{array}{l}\text { Small for Gestational Age } \\
<5^{\text {th }} \text { Centile }\end{array}$ & $72(12.8 \%)$ & $32(8.4 \%)$ & $2.04(1.11-3.75)$ \\
\hline $\begin{array}{l}\text { Small for Gestational Age } \\
<10^{\text {th }} \text { Centile }\end{array}$ & $109(19.3 \%)$ & $48(12.7 \%)$ & $1.81(1.11-3.00)$ \\
\hline $\begin{array}{l}\text { Neonatal intensive care } \\
\text { admission }\end{array}$ & $57(10.1 \%)$ & $19(5.97 \%$ & $2.79(1.29-5.73)$ \\
\hline
\end{tabular}

${ }^{*}$ Adjusted for BMI, maternal age, parity ${ }^{* *} \mathrm{P}<0.0001$

Conclusion Black ethnicity is associated with significantly worse pregnancy outcomes in women with CHT. There have been no 